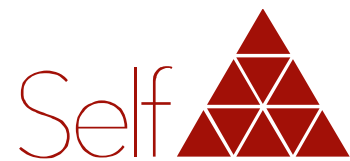

Revista do Instituto Junguiano de São Paulo

\title{
As doenças do coração e as emoções: conversações entre a psicossomática e a psicologia analítica
}

\author{
Lúcia Fátima Reolon dos SANTOS \\ Maria Inês Favarin PEREIRA \\ Caio Vinicius MARTINS \\ Cascavel, PR, Brasil.
}

\section{Resumo}

A plena compreensão da dinâmica existente entre as doenças cardíacas do homem contemporâneo e os seus conflitos emocionais e motivações inconscientes está ainda muito distante. Este trabalho tem como objetivo ampliar a compreensão dos significados e finalidades dessas doenças na vida das pessoas. Tal questão diz respeito à manifestação simbólica do conflito inconsciente através do sintoma, levando-se em consideração que este precisa da ação do psíquico e do somático, isto é, do emocional e do físico. Vivências ou conteúdos com cunho emocional significativo que não são verbalizadas ou liberadas de outra forma visível podem se manifestar no corpo, revelando assim o conteúdo negado, reprimido e inconsciente. $\bigcirc$

Conflito de interesses: Os autores declaram não haver nenhum interesse profissional ou pessoal que possa gerar conflito de interesses em relação a este manuscrito. coração, órgão essencial do corpo humano, bem como as emoções nele projetadas ou por ele expressas carregam importante simbologia. Seria um equívoco tratá-lo tão somente como um órgão, separando soma e psique, corpo e emoção. Julgamos de suma importância olhar o sintoma de modo diferenciado, analisando o que este quer expressar, ao invés de simplesmente optar pela medicalização da questão. É premente compreender o ser humano integralmente, com toda sua complexidade: um ser biológico, psíquico, emocional e espiritual.

\section{Descritores}

emoções, distúrbios do coração, medicina psicossomática, psicologia junguiana. 


\title{
Heartdisease and emotions: Conversations between psychosomatic and analytical psychology
}

\begin{abstract}
A full understanding of the dynamics existing between contemporary heart diseases and the emotional conflicts and unconscious motivations of contemporary man is still a long way off. This paper intends to broaden the understanding of the meanings and purposes of these diseases in people's lives. This question is related to the symbolic manifestation of unconscious conflict through the symptom, taking into consideration that the symptom involves psychic and somatic action, that is, the emotional and the physical. Experiences or significant emotional content that are not verbalized or visibly released may eventually manifest in the body, revealing denied, repressed, and unconscious content. The heart, the essential organ of the human body, as well as the emotions projected or expressed by it, carry important symbology. It would be a mistake to treat it only as an organ, separating body and psyche, body and emotion. We consider it extremely important to look at the symptom in a different way, analyzing what it wants to express rather than simply opting for medicalization of the issue. It is crucial for fully understanding the human being in all its complexity: a biological, psychic, emotional and spiritual being.
\end{abstract}

\section{Descriptors}

emotions, heart disorders, psychosomatic medicine, Junguian psychology. 


\section{Las enfermedades del corazón y las emociones: conversaciones entre psicosomática y la psicología analítica}

\section{Resumen}

Comprender de forma completa la dinámica entre la enfermedad del corazón del hombre moderno y sus conflictos emocionales y motivaciones inconscientes es aún algo lejano. Este trabajo tiene como objetivo ampliar la comprensión del significado y propósito de estas enfermedades en la vida de las personas. Esta cuestión se refiere a la manifestación simbólica del conflicto inconsciente a través de los síntomas, teniendo en cuenta que este necesita de la acción del psíquico y del somático, es decir, del emocional y del físico. Experiencias o contenidos con naturaleza emocional significativa que no son verbalizados o liberados de otra forma visible se pueden manifestar en el cuerpo, revelando así el contenido negado, reprimido e inconsciente. El corazón, órgano esencial del cuerpo humano, así como las emociones en él proyectadas o por él expresadas, cargan un importante simbolismo. Sería un error tratarlo simplemente como un órgano, que separa el soma y la psique, el cuerpo y las emociones. Consideramos muy importante tener en cuenta los síntomas de forma diferencial, analizando lo que este quiere expresar, en lugar de simplemente optar por la medicalización del problema. Es urgente comprender el ser humano de forma integral, en toda su complejidad: un ser biológico, psicológico, emocional y espiritual.

\section{Descriptores}

emociones, cardiomiopatías, medicina psicosomática, psicología junguiana. 


\section{Introdução}

As doenças cardiovasculares são as principais causas de mortes na população brasileira (Mansur \& Favarato, 2012). Um quarto dos pacientes não encontra nenhuma justificativa biológica para seu sofrimento físico, mesmo com os mais modernos exames, e, incrédulos, passam a fazer o que Morschhitzky e Sartor (2013) definem como "turismo médico". Já outros pacientes associam seus males a causas orgânicas, bem como a fatores psíquicos e sociais, interagindo com questões físicas e psíquicas. Por esse motivo é primordial que a medicina tenha um olhar voltado para o fenômeno físico-psíquico.

Este trabalho busca (i) ampliar a compreensão da relação entre as doenças do coração do homem contemporâneo e seus conteúdos inconscientes; (ii) ampliar o entendimento de como os sentimentos e emoções influenciam a origem dessas doenças; (iii) compreender como a conscientização e a elaboração desses conteúdos podem contribuir para o restabelecimento da saúde; e, aspirando a uma visão do ser humano em sua integralidade, entender a inter-relação entre os aspectos emocionais e as somatizações, na tentativa de alcançar seus significados.

Para Jung (2004) "A psique depende do corpo, e o corpo depende da psique." (p. 2; OC XVI/1: 1).

\section{A psicologia analítica e a psicossomática}

No entender de Penna (2004), a pesquisa na perspectiva da psicologia analítica "considera os fenômenos em seu âmbito individual [...] e coletivo [...], desde que revestidos de valor simbólico, seja para o indivíduo ou a coletividade que os produz e os vivencia psicologicamente" (p. 90). A compreensão do símbolo acontece a partir de sua elaboração. $\bigcirc$ símbolo conecta o mundo externo com o mundo interno: a metodologia junguiana propõe um método investigativo de ambos os fenômenos. $\mathrm{Na}$ prática psicoterápica, o foco é o aspecto subjetivo, "e visa a compreender a dinâmica psíquica a partir das manifestações individuais" (Penna, 2004, p. 84).

Aspectos da psique que se apresentam por meio de sintomas somáticos são estudados pela medicina psicossomática e/ou holística; pela psicologia médica, termo proposto pelo francês Pierre Schneider para designar o estudo e o ensino da relação médico-paciente; e pela psicologia da prática médica, proposta por Alonso Fernandez em uma tentativa de concepção mais abrangente.

A psicossomática diz respeito à inter-relação entre os processos físicos e psíquicos. 
Pensamento popular sabe que o corpo é influenciado pelas emoções. Com efeito, comumente usamos expressões verbais que evidenciam a estreita relação entre corpo e alma, tais como as anotadas por Morschhitzky e Sartor (2013):

A relação estreita entre corpo e alma reflete-se igualmente na linguagem. "O coração me salta pela boca", "fico sem ar", "algo está entalado em minha garganta", "tremo de raiva" são apenas alguns exemplos. Na palavra emoção encontra-se a palavra latina motio, que significa "movimento". Emoções não nos movem somente internamente, e sim, ativam também o nosso corpo e o levam a um estado de tensão. (p. 13)

Ou ainda:

A reação psicossomática certamente é uma forma saudável de experiência, pois cada emoção conduz a reações físicas e cada reação física gera determinadas emoções. As designações "doenças psicossomáticas" e "psicossomatoses", por sua vez se referem a uma forma patológica da relação corpo e alma, isto é, à interação de fatores físicos e psíquicos relativamente à formação e ao decurso de doenças. (Morschhitzky \& Sartor, 2013, p. 13)

No entender destes autores, não se trata de desconsiderar os aspectos biológicos, mas sim de considerar com mais atenção as questões emocionais e psicológicas. Para Hipócrates, as emoções podem influenciar significativamente um órgão, a ponto de o coração se contrair diante de aborrecimentos e relaxar em momentos de alegria. Para a medicina da Antiguidade, os fatores físicos e psíquicos tinham igual importância. Já na Idade Média, a lgreja Católica reforçou a ideia de cisão entre corpo e alma e, no século XVII, Descartes fundamenta esse dualismo. No século XX, os estudos da psicanálise freudiana provocam um movimento a partir do qual se iniciou a psicossomática da atualidade.

O termo "psicossomática" - derivado dos vocábulos grego psykhé (mente) e soma (corpo) - surgiu com Johann Heinroth em 1918. Sua consolidação se deu somente com Franz Alexander e a denominada Escola de Chicago, em meados do século XX.

A evolução da psicossomática aconteceu em três fases distintas, conforme relata Mello Filho et al. (2010):

a) inicial, ou psicanalítica, com predomínio dos estudos sobre a gênese inconsciente das enfermidades, sobre as teorias da regressão e sobre os benefícios secundários do adoecer, entre outras; b) intermediária, ou behaviorista, caracterizada pelo estímulo à pesquisa em homens e animais, tentando enquadrar os achados à luz das ciências exatas e dando um grande estímulo aos estudos sobre estresse; c) atual ou multidisciplinar, em que vem 
emergindo a importância do social e da visão da psicossomática como uma atividade essencialmente de interação, de interconexão entre vários profissionais de saúde. (p. 29)

No princípio, os estudos sobre a relação mente-corpo se restringiam a uma concepção reducionista, segundo a qual encontrar a causa e entender sua história eram o objetivo primordial. Entretanto, percebeu-se a necessidade de formas mais amplas de compreender a conexão entre o corpo e a psique.

Os conceitos conexos de alexitimia e pensamento operatório foram respectivamente estabelecidos pelas escolas Americana e Francesa. Alexitimia se refere a indivíduos com limitações para lidar com emoções, pois não possuem vocabulário para nomear o que sentem, tornando-se mais vulneráveis às manifestações somáticas. Já "os portadores de pensamento operatório têm um mundo interno pobre e investem intensamente na realidade externa, da qual passam a ser dependentes ou "hiperadaptados'" (Silva \& Caldeira, 2010, p. 158). Mesmo em idade adulta, o indivíduo pode apresentar um repertório pobre de palavras e, por esse motivo, não ser capaz de expressar o que está sentindo. A pessoa não dispõe de símbolos para explicitar o que deseja, tampouco consegue representar o sentimento.

Crianças se utilizam dos sonhos e fantasias para poder se expressar. As fantasias têm função reguladora dos processos internos. $\bigcirc$ bebê se relaciona com a mãe e é através do corpo que vai se apropriando do mundo. As respostas as suas reações fazem com que a criança reconheça as suas emoções. Isso acontece porque o bebê se sente como extensão da mãe, reproduzindo os sentimentos desta e sofrendo suas consequências, no corpo físico, por não ter ainda mecanismo de expressão mais adequado. Após essa fase, a criança começa a perceber que tem vontade própria e inicia o que Silva e Caldeira (2010) entendem como processo de individualização. Pessoas que não tenham sido devidamente cuidadas e acolhidas podem não reconhecer e, portanto, não saber nomear ou representar o que sentem.

A psicossomática se refere a toda expressão psíquica via soma. Com efeito, Jung (1991) afirma que:

A enigmática unidade da natureza viva traz consigo que a característica corporal não é simplesmente corporal e a característica psíquica não é simplesmente psíquica, pois a continuidade da natureza não conhece aquelas incompatibilidades e distinções que a razão humana precisa colocar a fim de entender. A separação entre corpo e alma é uma operação artificial, uma discriminação que se baseia menos na natureza das coisas do que na peculiaridade da razão que conhece. A intercomunicação das características corporais e psíquicas é tão íntima que podemos tirar conclusões não só a partir da constituição do corpo sobre a constituição da psique, mas também da particularidade psíquica sobre as correspondentes formas corporais dos fenômenos. É verdade que o último processo é bem mais difícil, não porque o corpo é menos influenciado pela psique do que a psique pelo corpo, mas porque, partindo da psique, temos 
que concluir do desconhecido para o conhecido, enquanto que no caso inverso temos a vantagem de começar pelo conhecido, ou seja, pelo corpo visível. (p. 483, OC VI: 979)

\section{O sintoma é o símbolo do conflito}

A perspectiva analítica compreende os sintomas como expressões simbólicas que se originam nos complexos e que revelam uma disfunção na relação entre o eu e o si-mesmo. Contudo, esse mesmo "sintoma-símbolo compensa o erro e aponta sincronicamente a 'correção' a ser feita, isto é, o conteúdo inconsciente que precisa ser integrado à consciência" (Ramos, 2006, p. 76 77).

Um dos principais objetivos da psicologia analítica é levar o indivíduo a alcançar a totalidade psíquica, o si-mesmo ou self, a singularidade do seu ser enquanto pessoa única que é. Ao processo que conduz a este objetivo Jung denominou individuação: "A individuação, em geral, é o processo de formação e particularização do ser individual e, em especial, é o desenvolvimento do indivíduo psicológico como ser distinto do conjunto, da psicologia coletiva." (Jung, 1991, p. 427; OC VI: 853)

Individuação não é sinônimo de isolamento e excesso de individualismo, mas antes, a pessoa que desenvolve seu mito pessoal e sua personalidade natural é inevitavelmente conduzida a um relacionamento coletivo mais intenso e abrangente.

A essa personalidade natural se sobrepõe a persona, uma máscara (ou conjunto de máscaras) que atua adequando o sujeito às exigências e padrões gerados nas expectativas sociais. Assim, a verdadeira personalidade do indivíduo, sua verdadeira alma, se acha em boa parte inconsciente.

Segundo Stein (2000):

Para Jung, o si-mesmo é transcendente, o que significa que não é definido pelo domínio psíquico nem está contido nele, mas situase, pelo contrário, além dele e, num importante sentido, define-o. [...] $\bigcirc$ si-mesmo forma a base para o que no sujeito existe de comum com o mundo, com as estruturas do Ser. No si-mesmo, sujeito e objeto, o ego e o outro, juntam-se num campo comum de estrutura e energia. (pp. 137-138)

No processo de individuação o desenvolvimento ou fortalecimento do eu se dá por meio da integração de conteúdos inconscientes à consciência, em um processo de assimilação psíquica.

Na Antiguidade, a doença era percebida como um castigo e era curada por meio de rituais específicos para se retirar o mal da pessoa. Ramos (1995) esclarece essa prática: 
A cura acontecia, e acontece, através dos rituais onde a pintura de símbolos mandálicos, a doença e o canto eram e são os elementos principais. A apresentação dos símbolos para o doente evoca na psique a presença do divino e da força curadora que estava em desequilíbrio devido a alguma ofensa feita pelo doente a um deus. (p. 28)

Tanto os ritos e formas de cura quanto a simbologia da doença e a forma de enfrentá-la objetivam levar o doente as suas origens, a sua essência, propiciando um encontro consigo mesmo, restabelecendo a harmonia.

Ramos (1995) afirma:

Observamos, hoje, que o homem e a psicologia perderam contato com a finalidade da doença, com a importância e valor especiais desta, e com o papel central que os símbolos têm de ligar a consciência a forças curadoras que estão no próprio indivíduo. Nossa visão dicotomizada cinde o homem em duas metades, corpo-psique, e tenta trabalhar com uma delas por vez, como se a outra não existisse. Como resultado, o homem passivo diante de seu sofrimento assume papel de vítima do acaso e, inconsciente dos fatores que o levaram ao desequilíbrio apela para soluções externas e artificiais. (p. 30)

A doença, portanto, é compreendida como uma manifestação simbólica dos conteúdos inconscientes, contribuindo para o processo de desenvolvimento e individuação. Ramos (1995) esclarece que "a doença seria assim, uma expressão simbólica, uma forma de o organismo expressar uma desarmonia entre, por exemplo, um desejo e uma resistência, entre um impulso e uma negação" (p. 45).

A incompatibilidade entre o que se deseja e o que se vivencia - ou mesmo o medo das consequências das escolhas necessárias da vida - apresenta-se por meio de sensações como tensão e estresse. A falta de consciência desses conflitos pode vir a se agravar e a se manifestar somaticamente como uma doença cardíaca. "A dor no peito pode ser o primeiro símbolo a chegar à consciência, como a melhor expressão desse conflito e, ao mesmo tempo, é uma tentativa de chamar a atenção do indivíduo para o desvio do ego e sua totalidade" (Ramos, 1995, p. 45). Portanto, o olhar interessado e reflexivo do indivíduo sobre o seu corpo, sobre os sintomas-símbolo que este apresenta, tem crucial importância no processo de cura.

Por meio dos sintomas é possível perceber que "no corpo, o sintoma é o símbolo que pode expressar o desenvolvimento unilateral e que, por sua vez, pode levar a uma maior consciência corporal" (Ramos, 1995, p. 129), mostrando, assim, uma direção. Jung (2002), por sua vez, já afirmara que há "casos, muito comuns e conhecidos da Medicina, nos quais certos sintomas clínicos desaparecem quando seus respectivos conteúdos inconscientes se tornam conscientes". (p. 171; OC VIII/2: 440)

Para Ramos (2006): 
Na medida em que o símbolo implica a união de algo consciente com algo inconsciente, ele sempre provoca emoção, isto é, um "movimento para fora" (e + moção), movimento do sistema nervoso vegetativo, simpático e parassimpático. Dessa forma, temos aqui a chave da psicossomática: por meio do símbolo atingimos as camadas orgânicas profundas e inacessíveis à consciência. (pp. 189-190)

Os conteúdos inconscientes atuam sobre a vida e o corpo do indivíduo independentemente de ele ter consciência disso ou não. Para Jung (2015), "o inconsciente possui [...] não apenas conteúdos reprimidos, mas todo o material psíquico que subjaz ao limiar da consciência". (p. 15; OC VII/2: 203)

inconsciente está em atividade constante, sendo que, em primeiro lugar, em uma relação compensadora com a consciência. No entanto, conteúdos do inconsciente, em casos patológicos, podem se tornar completamente autônomos.

Segundo Ramos (2006):

O corpo simbólico, definido como o conjunto de significados psicológicos do corpo somático, pode ser vivido passiva ou ativamente. Quando é constelado passivamente, temos, por exemplo, a formação de sintomas e o surgimento de fantasias; quando é vivido ativamente, temos o estabelecimento de uma relação com o símbolo emergente, integrando-o na consciência. (p. 67)

Jung (2013) define a consciência "como a relação dos fatos psíquicos com o eu" (p. 24; OC XVIII/1: 18), e o eu constitui-se em um "complexo formado primeiramente por uma percepção geral de nosso corpo e existência e, a seguir, pelos registros de nossa memória" (Jung, 2013, p. 24; OC XVIII/1: 18). A consciência surge do inconsciente.

Compreender a inter-relação dos componentes da psique humana é fundamental para se lidar com sintomas ou doenças psicossomáticas. A manifestação sintomática a partir de questões psíquicas acontece quando um complexo é atingido: os sintomas têm origem nos complexos e sua expressão corresponde à constelação do complexo.

Para Jung (2002):

O que é, portanto, cientificamente falando, um "complexo afetivo"? É a imagem de uma determinada situação psíquica de forte carga emocional e, além disso, incompatível com as disposições ou atitude habitual da consciência. Esta imagem é dotada de poderosa coerência interior e tem sua totalidade própria e goza de um grau relativamente elevado de autonomia, vale dizer: está sujeita ao controle das disposições da consciência até um 
certo limite e, por isto, comporta-se, na esfera do consciente, como um corpus alienum [corpo estranho], animado de vida própria. Com algum esforço de vontade, pode-se, em geral, reprimir o complexo, mas é impossível negar sua existência, e na primeira ocasião favorável ele volta à tona com toda a sua força original. (p. 31; OC VIII/2: 201)

Os complexos estão geralmente associados à sombra da personalidade: a "personificação de certos aspectos inconscientes da personalidade que poderiam ser acrescentados ao complexo do ego, mas que, por várias razões não o são" (von Franz, 1985, p. 11). Para além da parte obscura, não vivida e reprimida do eu, a sombra é constituída de tudo aquilo que faz parte da pessoa, mas que esta desconhece, constituindo-se tanto de elementos pessoais, quanto de elementos coletivos profundamente inconscientes.

Para Dahlke (2007) "a sombra é uma parte necessária de nossa totalidade, somente podemos tornar-nos sãos, no sentido de íntegros, através justamente de sua integração" (p. 19). Os sintomas de taquicardia, dores, aperto no peito ou de uma angústia inexplicável podem estar relacionados a situações de sofrimento, tais como perdas, solidão, estresse, dificuldades de relacionamentos e todos os fatos da vida com os quais o indivíduo tem dificuldade de lidar. Ainda assim, a doença é um trajeto a ser percorrido que diz respeito unicamente ao indivíduo por ela acometido. É preciso muito esforço do indivíduo, para interpretar e encontrar o significado da doença em sua vida.

Pode-se fazer uma analogia entre os sintomas e os movimentos de sístole e diástole: um coração oprimido, contraído, fechado em si mesmo estará cego perante o simbolismo de sua sintomatologia, podendo, inclusive, projetar tudo o que lhe é incomodo e difícil para outrem. Por sua vez, um coração relaxado, que se dilata e se expande (acolhedor), que assume a responsabilidade pelo próprio destino, compreende a doença como oportunidade de reflexão e mudança. Tais reflexões se encontram com a afirmação de Chevalier et al. (2015): "o duplo movimento (sístole e diástole) do coração faz dele ainda o símbolo do duplo movimento de expansão e reabsorção do universo" (p. 281). A consciência e a atitude do indivíduo frente a estes movimentos podem influenciar sua saúde ou seu adoecimento.

Jung (2013) percebeu que havia outra "força" atuando na psique humana: o inconsciente coletivo, composto por imagens psíquicas primordiais, os arquétipos. Um arquétipo é sempre coletivo e, segundo Jung (1991), o seu simbolismo, seu conteúdo ou significado não é pessoal, mas sempre será "comum a todos os povos e tempos" (p. 419; OC VI: 832). Jung (2015) pontua que "[...] devemos afirmar que o inconsciente contém, não só componentes de ordem pessoal, mas também impessoal, coletiva, sob a forma de categorias herdadas ou arquétipos" [destaques no original] (p. 26; OC VII/2: 220). 


\section{A simbologia do coração}

No que se refere à simbologia do coração, tradições do Oriente e do Ocidente consideram este órgão como centro, quer seja do conhecimento e da intuição, quer seja dos sentimentos e valores afetivos. O coração é a expressão do arquétipo central tanto em sua origem como nas representações culturais mitológicas. A simbologia deste órgão traz uma grande carga psicológica, e não se pode separá-lo em corpo e emoção, ou seja, ele não pode ser visto somente como um órgão do corpo humano.

A etimologia da palavra coração se origina do termo indo-europeu krd ou kered e, no grego, deriva para kardia para, então, se desenvolver nos termos médicos: cardíaco, cardiograma, endocárdio, entre outros; e do latim cor, o qual se desenvolve para cordial, acordar, concordar, coragem e outros.

O simbolismo do coração está atrelado às experiências pessoais e às ideias da coletividade com seus mitos e símbolos arquetípicos; ele inclui a visão de que as polaridades orgânico-corporal e psíquico-comportamental são harmônicas.

Quando uma criança está com medo e chorando, sendo acolhida pela mãe que está tranquila, ela geralmente também se tranquiliza e seu ritmo cardíaco se restabelece. Os sentimentos tais como solidão, amor e carinho também tendem a estar atrelados ao ritmo cardíaco que diante de uma ameaça dispara, retornando à normalidade quando sente novamente a segurança.

Toda emoção coloca o organismo em movimento e o que se percebe, em primeiro lugar, é a mudança no ritmo cardíaco e na respiração. Sentimentos como a raiva, a ansiedade e o medo se destacam como os principais elementos capazes de provocar a somatização de problemas cardíacos. Nessas condições, diante da preparação do organismo para a luta ou a fuga, o coração sofre uma aceleração e aumento do volume para conseguir responder à situação. Em condições normais, tais reações são manifestadas imediatamente, mas, passado algum tempo, o equilíbrio do organismo se restabelece. Ramos (1995) ainda ressalta que "[...] se o medo ou outro fator impedir a ação, todas as alterações, inclusive cardiológicas, serão reprimidas e passarão a subsistir por certo tempo, causando estresse para o organismo" (p. 109).

Mesmo antes de se conhecer as reais funções do coração, ele já era visto como o filtro das emoções: estas são experimentadas fisicamente, gerando um desequilíbrio em todo o sistema que integra corpo-alma-psique, ocasionando, por fim, a enfermidade do órgão. Nessa perspectiva Otto, Amui e Mestre (2012) ressaltam que: "Alterações emocionais e psíquicas causadas pelo processo de adoecer fazem com que os pacientes possam alcançar um processo de autotransformação, voltando-se para o si-mesmo 
através da ampliação da consciência e do desenvolvimento da sua psique, num processo de individuação" (p. 117).

O coração e as emoções que a ele se associam estão repletos de simbologia, pois o órgão cardíaco é a expressão do arquétipo central.

Vejamos que:

Para os maias, astecas, egípcios e hindus entre outros [o coração] é o centro da vida e da renovação. No Hinduísmo é o lugar da moradia de Brahman e de Krishna. Dentro dele oculta-se o Self, a semente, e nele tudo está contido. Ou, entre os astecas, maias e egípcios, liga-se ao arquétipo do Pai, enquanto o sol, centro do nosso sistema solar, de onde vem o calor e a vida. (Ramos, 1995, p. 122)

Já na filosofia taoísta, compreende-se o coração como o lugar da consciência celeste. $\bigcirc$ céu a que se refere "não é o amplo céu azul, mas o lugar em que a corporeidade é gerada na casa do criativo" (Jung \& Wilhelm, 1983, pp. 98-99). É do coração que se origina o sentido da vida. $\bigcirc$ método reflexivo quando realizado corretamente, ou seja, quando coloca a luz celeste em movimento, conduz a uma completa tranquilidade, permitindo que o coração celeste se manifeste por si mesmo. Assim, "quando o sentimento é tocado e se exterioriza diretamente, o homem nasce como ser vivente originário" (Jung \& Wilhelm, 1983, p. 99).

Nessa mesma direção, percebendo a necessidade da iluminação de conteúdos inconscientes, de que estes sejam trazidos à luz, pois, justamente pelo fato de estarem inconscientes, buscam outras vias para se expressarem, Jung e von Franz (2012) fazem a seguinte reflexão:

Como o sol e o ouro representam na alquimia conceitos equivalentes, assim também a solificatio (solificação, iluminação) significa que "o que está dentro" da cabeça - seja o que for que se entenda por isso - é mudado em luz, substância preciosíssima e terra branca. Também o coração brilha "como um "carbúnculo" (pedra preciosa). [...]. Neste caso a alegoria é clara: com a cabeça iluminada o coração se inflama de amor. (p. 221, OC XIV/2: 275)

Para a filosofia Tantra Yoga o coração é a fonte da força do amor. É no coração que se interligam os opostos masculino e feminino, e quando este núcleo é desperto, ocorre uma maior sensibilidade ao próprio sofrimento e ao sofrimento do outro. Tal acontecimento provoca também uma maior harmonização entre o indivíduo e a natureza, desenvolvendo uma personalidade mais autêntica; todo processo flui de forma suave e tranquila integrando, nesse caso, anima e animus, os aspectos psíquicos feminino e masculino da existência humana. 
Com perspectiva semelhante, os relatos do Antigo Testamento apresentam o coração "[...] como lugar da mente e da vida intelectual, como sede dos sentimentos e como centro da vida moral e religiosa" (Ramos, 1995, p. 86). Nesse sentido, leva os fiéis a se lembrarem das coisas que Deus ensinou. No que diz respeito aos sentimentos, o caminho é o da renovação e o do desenvolvimento de um coração autêntico e puro, que busca a plenitude da presença divina para suprir a dor da ausência. Por sua vez, o livro do profeta Ezequiel apresenta a ideia de se extrair o coração duro e substituí-lo por um coração de carne; da mesma forma Moisés admoesta à circuncisão do coração: "Vocês devem circuncidar o prepúcio de seu coração e não mais serem teimosos" (Ramos, 1995, p. 87). Tal exortação corresponde à flexibilidade e à aceitação de mudanças e do novo, saindo do modo rígido e estanque de se viver; é um entregar-se; a representação da união entre o eu e o arquétipo central, reunindo o humano com o divino, em uma aliança que auxilia no processo de individuação do homem, dando-lhe o caráter particular do ser, em busca de equilíbrio entre o eu e o inconsciente.

\section{Considerações finais}

O coração é um órgão de formidável simbologia. É visto tanto como órgão material como emocional e ambos se afetam mutuamente por meio de mudanças físicas e/ou psicológicas. Neste trabalho buscou-se conhecer de maneira mais aprofundada os aspectos relacionados às doenças do coração do homem moderno e aos conteúdos inconscientes. A possibilidade de elaboração desses conteúdos, a partir da tomada de consciência da influência dos sentimentos e das emoções, é condição que favorece um novo olhar, reduzindo ou eliminando os fatores causadores de angústia e de sofrimento emocional e físico.

Quando estados emocionais corriqueiros são acompanhados de modificações somáticas, é difícil resistir à tendência de estabelecer nexos causais entre, por exemplo, a tristeza e o choro, a raiva e a azia, o medo e a palidez, a alegria e a mímica do riso. A somatização é determinada em maior ou menor grau por aspectos reprimidos do inconsciente e envolve diversos mecanismos, em especial, os conteúdos reprimidos que precisam ser integrados à psique. Quando esses conteúdos são trazidos à consciência, as somatizações diminuem de intensidade ou até mesmo podem vir a serem curadas e a desaparecer.

Olhar o sintoma de forma simbólica permite tentar perceber o ser humano em toda sua complexidade: física, mental, emocional e espiritual. 


\section{Referências}

Chevalier, J., Gheerbrant, A., Barbault, A., Bayle, D., Caroutch, Y., Chevalier, M., ... Volguine, A. (2015). Dicionário dos Símbolos: mitos, sonhos, costumes, gestos, formas, figuras, cores, números. Rio de Janeiro: José Olympio.

Dahlke, R. (2007). A doença como linguagem da alma: os sintomas como oportunidades de desenvolvimento. São Paulo: Cultrix.

Jung, C. G. (1991). Tipos psicológicos. In Obras Completas (Vol. VI). Petrópolis: Vozes.

Jung, C. G. (2002). A natureza da psique. In Obras Completas (Vol. VIII/2). Petrópolis: Vozes.

Jung, C. G. (2004). A prática da psicoterapia: contribuições ao problema da psicoterapia e à psicologia da transferência. In Obras Completas (Vol. XVI/1). Petrópolis: Vozes.

Jung, C. G. (2013). A vida simbólica: escritos diversos. In Obras Completas (Vol. XVIII/1). Petrópolis: Vozes.

Jung, C. G. (2015). O eu e o inconsciente. In Obras Completas (Vol VII/2). Petrópolis: Vozes.

Jung, C. G., \& von Franz, M. L. (2012). Mysterium Coniunctionis: pesquisas sobre a separação e a composição dos opostos psíquicos na alquimia. In C. G. Jung, Obras Completas (Vol. XIV/2). Petrópolis: Vozes.

Jung, C. G., \& Wilhelm, R. (1983). O segredo da flor de ouro: um livro de vida chinês. Petrópolis: Vozes.

Mansur, A. P., \& Favarato, D. (2012, junho 28). Mortalidade por doenças cardiovasculares no Brasil e na Região Metropolitana de São Paulo: atualização 2011 [Versão eletrônica]. Arquivos Brasileiros de Cardiologia, 99(2) Recuperado em 08 de maio de 2017, de http://www.scielo.br/scielo.php?script=sci_arttext\&pid=S0066782X2012001100010

Mello Filho, J., Burd, M., Eksterman, A., Hoirisch, A., Mello, A. M. de, Kathalian, A. ... Eksterman, V. F. (2010). Psicossomática hoje (2a ed.). Porto Alegre: Artmed.

Morschhitzky, H., \& Sartor, S. (2013). Quando a alma fala através do corpo: compreender e curar distúrbios psicossomáticos. Petrópolis: Vozes.

Otto, F. F., Amui, J. M., \& Mestre, M. (2012, janeiro/junho). Coração e alma: vida e outros símbolos das doenças cardíacas na realidade hospitalar [Versão eletrônica]. Rev. SBPH, 15(1), 114-133. Recuperado em 08 de maio de 2017, de http://pepsic.bvsalud.org/scielo.php?script=sci_arttext\&pid=S151608582012000100008 
Penna, E. M. D. (2004). O paradigma junguiano no contexto da metodologia qualitativa de pesquisa. Psicologia USP, 16(3), 71-94.

Ramos, D. G. (1995). A psique do coração: uma leitura analítica do seu simbolismo. São Paulo: Cultrix.

Ramos, D. G. (2006). A psique do corpo: a dimensão simbólica da doença. São Paulo: Summus.

Silva, A. F. R., \& Caldeira, G. (2010). Alexitimia e pensamento operatório: a questão do afeto na psicossomática. In J. de Mello-Filho (Org.), Psicossomática hoje (pp. 158-166). Porto Alegre: Artmed.

Stein, M. (2000). Jung - o mapa da alma: uma introdução. São Paulo: Cultrix. von Franz, M. L. (1985). A sombra e o mal nos contos de fada. São Paulo: Paulus.

Minicurrículos: Lúcia Fátima Reolon dos Santos - Bacharel em Teologia pela Faculdade Missioneira do Paraná (Famipar); especialista em Ensino Religioso pela Famipar; graduanda em Psicologia pela Universidade Paranaense (Unipar); pós-graduanda em Psicologia Analítica: Clínica Junguiana pela Unipar; pós-graduanda em Imaginação Ativa (2017-2019), pelo Ichthys Instituto de Psicologia Analítica (Curitiba/PR). E-mail: luciareolon@hotmail.com

Maria Inês Favarin Pereira - Graduada em Letras (Português/Espanhol), pela Universidade Paranaense (Unipar); pós-graduada em Língua Espanhola, pela Faculdade Anhanguera Unipan; graduanda em Psicologia pela Unipar. Professional and Self Coaching, pelo Instituto Brasileiro de Coaching (IBC). Master Practitioner e Treiner em Programação Neurolinguística, pelo Instituto Xaris.

Caio Vinicius Martins - Psicólogo clínico. Mestre em Psicologia Clínica pelo Núcleo Junguiano da Pontíficia Universidade Católica de São Paulo; graduado em Psicologia pela Pontíficia Universidade Católica do Paraná. Docente do curso de Psicologia na Universidade Paranaense (Unipar); supervisor em estágio clínico; coordenador do curso de "Especialização em Psicologia Analítica: Clínica Junguiana" da Unipar. 